\title{
Effect of intravenous hydrocortisone on nocturnal airflow limitation in childhood asthma
}

\author{
A.M. Landstra*, H.M. Boezen", D.S. Postma", W.M.C. van Aalderen ${ }^{+}$
}

Effect of intravenous hydrocortisone on nocturnal airflow limitation in childhood asthma. A.M. Landstra, H.M. Boezen, D.S. Postma, W.M.C. van Aalderen. (C) ERS Journals Ltd 2003.

ABSTRACT: Low endogenous cortisol levels appear to contribute to the pathophysiology of nocturnal asthma. Lower cortisol levels are associated with lower forced expiratory volume in one second (FEV1) levels in children with asthma. The aim of the present study was to identify whether substitution of low serum cortisol with intravenous hydrocortisone decreases 24-h FEV1 variation and/or indirect measures of airway inflammation.

Hydrocortisone was given over $24 \mathrm{~h}$ in a double-blind randomised crossover design to 26 subjects. FEV1 was measured every $4 \mathrm{~h}$ during $24 \mathrm{~h}$; blood eosinophils and airway responsiveness to methacholine and adenosine $5^{\prime}$-monophosphate (AMP) were measured at 04:00 $\mathrm{h}$ and 16:00 $\mathrm{h}$.

Cortisol levels increased during the night and morning hours. FEV1 values were higher at all time points in children with nocturnal asthma $(n=10 ; 24-h$ FEV1 variation $\geqslant 15 \%$ ) which was significant at $08: 00 \mathrm{~h}$, unlike in the non-nocturnal asthma (NA-) group $(n=16)$. Numbers of eosinophils $\left(10^{9} \cdot \mathrm{L}^{-1}\right)$ at $04: 00 \mathrm{~h}$ decreased in the asthma group (median 0.61 (range $0.05-1.42)$ versus $0.52(0.05-1.79)$ ). Provocative dose causing a 20\% fall in FEV1 (PD20) methacholine did not change, whereas PD20 AMP improved only at 16:00 $h$ in the NA- group $(72.0(0.13-144.0)$ versus 144.0 (2.25144.0) $\left.\mathrm{mg} \cdot \mathrm{mL}^{-1}\right)$.

These results show that substitution of lower endogenous 24-h values of cortisol contribute to higher forced expiratory volume in one second values and a decrease of blood eosinophils as an inflammatory marker in more severe airway obstruction.

Eur Respir J 2003; 21: 627-632.
*Dept of Paediatrics, Rijnstate Hospital, Arnhem, " Dept of Epidemiology, University of Groningen, and Dept of Pulmonology, University Hospital, Groningen, and ${ }^{+}$Dept of Paediatric Pulmonology, Emma Children's Hospital, Academic Medical Centre, Amsterdam, The Netherlands.

Correspondence: A.M. Landstra

Dept of Paediatrics

Rijnstate Hospital

PO box: 95556800

TA Arnhem

the Netherlands

Fax: 31263786147

E-mail: amlandstra@hetnet.nl

Keywords: Asthma

children

serum cortisol

Received: September 162002

Accepted after revision: November 112002

This study was supported by the Dutch Asthma Foundation (Grant 94.115) and Stichting, Astma Bestrijding.
The pathogenesis of nocturnal symptoms in children and adults with asthma is still not fully understood despite several proposed pathogenic mechanisms [1-10]. Nocturnal symptoms result from an overnight increase in airflow limitation. A number of studies have indicated that this enhanced airflow limitation may be due to increased airway inflammation particularly at night, as shown by a higher number of interstitial eosinophils in transbronchial biopsies [2], or indirectly measured as increased blood eosinophils and urinary $N^{\tau}$-methylhistamine overnight [7]. Other studies in children, as well as in adults, with asthma have shown an increase in airway responsiveness overnight $[11,12]$. In contrast, some of the current authors' previous studies $[6,13]$ have elucidated that inflammation is increased both during the day and the night. This subsequently leads to increased airflow limitation at night by a lack of bronchodilating forces.

Another factor suggested to contribute to increased airway inflammation is a lower serum cortisol level in asthmatic patients compared with healthy individuals [14-16]. Epidemiological studies in adults with asthma support this hypothesis. SPARRow et al. [17] showed lower levels of serum cortisol to be associated with lower forced expiratory volume in one second (FEV1) values and a more rapid decline in lung function. KAUFFMANN et al. [18] recently suggested that low endogenous cortisol is a possible risk factor for nocturnal symptoms of asthma. In order to establish the role of serum cortisol in the nocturnal fall in FEV1 in children with asthma, the present authors found in the first part of this study that lower cortisol levels are indeed associated with a lower level of FEV1 [19]. To substantiate this hypothesis of a role for cortisol in nocturnal asthma, the present authors have assessed whether substitution of low serum cortisol levels with intravenous hydrocortisone (HC) would lead to a decrease of the 24-h FEV1 variation, and/or improvement of inflammatory parameters during the night. Therefore, in a doubleblind, randomised, crossover study, low-dose HC was infused intravenously over a 24 -h period. The change in FEV1 was measured at six time points during these $24 \mathrm{~h}$ and blood eosinophil numbers and airway responsiveness to methacholine and adenosine $5^{\prime}$-monophosphate (AMP) was measured at 04:00 and 16:00 $\mathrm{h}$.

\section{Methods}

\section{Subjects with asthma}

Twenty-six children with stable asthma, aged 7-16 yrs, with a history of episodic wheezing, allergy and airway responsiveness to histamine (provocative concentration causing a $20 \%$ fall in FEV1 (PD20) $\leqslant 8 \mathrm{mg} \cdot \mathrm{mL}^{-1}$ histamine) were studied [19]. All patients entered the study after they had stopped their inhaled corticosteroids for 2 weeks, and their long-acting $\beta_{2}$-agonists for 5 days before the onset of the study. Shortacting $\beta_{2}$-agonists were withheld $8 \mathrm{~h}$ before the study. No oral corticosteroids were used for $\geqslant 2$ months before the study.

Informed consent was obtained from all children and their 
parents. The study was approved by the Medical Ethical Committee of the University Hospital of Groningen.

\section{Study design}

Saline (as a placebo) or $\mathrm{HC}(30 \mu \mathrm{g} \cdot \mathrm{m}$ body surface $\operatorname{area}^{-2} \cdot 24 \mathrm{~h}^{-1}$ ) was intravenously administered in a randomised, double-blind, crossover design. Measurements under saline or HC infusions were separated by 1 week. The pharmacist who prepared the different solutions also performed the randomisation procedure.

At day 1, children arrived at the hospital at $19.30 \mathrm{~h}$ and remained until 17:00 $\mathrm{h}$ the next day. An intravenous line was placed for taking blood samples. Blood samples were obtained before FEV1 measurements at 20:00, 00:00, 04:00, 08:00, 12:00 and 16:00 h. PD20 methacholine and circulating eosinophils were measured at 04:00 and 16:00 h. At day 3, the AMP provocation was performed at 16:00 and 04:00h. The children received the same intravenous solution at day 1 and day 3.

The group of asthmatic children with an FEV1 variation $\geqslant 15 \%$ (highest-lowest/mean FEV1 \% predicted) was defined to have nocturnal asthma (NA+); those with an FEV1 variation $<15 \%$ were defined as having no nocturnal asthma (NA-).

\section{Measurements}

The measurements of serum cortisol, blood eosinophil numbers, FEV1 values and the inhalation-provocation tests have been described in the current authors' earlier paper [19]. For the inhalation-provocation test, doubling concentrations of $0.15-39.3 \mathrm{mg} \cdot \mathrm{mL}^{-1}$ methacholine bromide or $0.04-160 \mathrm{mg} \cdot \mathrm{mL}^{-1}$ AMP were used after inhalation of $0.9 \%$ sodium chloride solution.

Baseline FEV1 values have been measured under saline. Because of the double-blind randomised design approximately one-half of the patients received the intravenous $\mathrm{HC}$ in the first week.

\section{Statistical analysis}

Normal distribution was checked visually by probability plots of the residuals and tested formally using KolmogorovSmirnov. Differences between groups (NA+ and NA-) were tested using parametric or nonparametric tests as appropriate. Within-group differences in FEV1 \% pred (at six time points) under $\mathrm{HC}$ substitution $(\mathrm{HC}+)$ and placebo (HC-) were tested using paired t-tests, and differences in eosinophil counts (at 04:00h and 16:00h), PD20 methacholine and PD20 AMP responsiveness (at 04:00h and 16:00h) were tested using the Wilcoxon Signed Ranks tests. A p-value $<0.05$ was considered significant. Data are presented as median (range) or mean \pm SD.

\section{Results}

\section{Subjects}

Patient characteristics are summarised in table 1. Twentysix children with asthma were included in the study. Ten children had nocturnal asthma (NA+) with a 24-h FEV1 variation $\geqslant 15 \%(25.3 \%(15.9-45.4 \%))$. Sixteen children had no nocturnal asthma (24-h FEV1 variation $<15 \%$ (NA-)). Their FEV1 variation was $8.9 \%$ (5.1-14.9\%). FEV1 \% pred
Table 1.-Patient characteristics

\begin{tabular}{lcc}
\hline & $\mathrm{NA}+$ & $\mathrm{NA}-$ \\
\hline Subjects n (male) & $10(6)$ & $16(9)$ \\
Age yrs & $13.1 \pm 1.4$ & $13.0 \pm 2.2$ \\
FEV1 \% pred & $86.7 \pm 10.1^{*}$ & $91.3 \pm 10.9^{*}$ \\
FEV1 \% pred 04:00 h & $80.8 \pm 14.7$ & $89.9 \pm 11.7$ \\
FEV1 \% pred 16:00 h & $90.1 \pm 10.6$ & $92.7 \pm 11.2$ \\
Eosinophils 04:00 h $10^{9} \cdot \mathrm{L}^{-1}$ & $0.79(0.05-1.42)$ & $0.60(0.08-0.90)$ \\
Eosinophils $16: 00 \mathrm{~h} 10^{9} \cdot \mathrm{L}^{-1}$ & $0.65(0.01-1.56)$ & $0.39(0.05-0.77)$ \\
Atopy \% & 100 & 100 \\
\hline
\end{tabular}

Data are presented as mean \pm SD or median (range) unless otherwise stated. FEV1: forced expiratory volume in one second; NA+: children with nocturnal asthma defined as a 24-h FEV1 variation $\geqslant 15 \%$; NA-: children without nocturnal asthma defined as a $24-\mathrm{h} \mathrm{FEV} 1$ variation $<15 \%$. * : $\mathrm{p}<0.05$.

over a 24-h period was significantly different between the $\mathrm{NA}+$ and NA- group $(86.7 \pm 10.1$ versus $91.3 \pm 10.9)$. Eosinophil counts at 16:00 $\mathrm{h}$ and $04: 00 \mathrm{~h}$ did not differ significantly between the $\mathrm{NA}+$ and the NA- group at baseline $(16: 00 \mathrm{~h}$ : $0.65(0.01-1.56)$ versus $0.39 \quad(0.05-0.77) ; 04: 00 \mathrm{~h}: 0.79$ $(0.05-1.42)$ versus $0.60(0.08-0.90))$.

\section{The effect of hydrocortisone infusion on serum cortisol levels}

Administration of intravenous HC significantly increased serum cortisol levels, when compared with values obtained during the saline day at 00:00, 04:00, 08:00 and 12:00 h. Only the 16:00 $\mathrm{h}$ values with and without $\mathrm{HC}(\mathrm{HC}+$ and $\mathrm{HC}-$, respectively) infusion were in the same range (HC- versus $\mathrm{HC}+$ : $243 \pm 126$ versus $\left.367 \pm 133 \mathrm{nmol} \cdot \mathrm{L}^{-1}\right)(\mathrm{fig} .1)$.

\section{The effect of hydrocortisone infusion on forced expiratory volume in one second values}

In the $\mathrm{NA}+$ group, intravenous $\mathrm{HC}+$ infusion was consistently associated with higher FEV1 values at all time points compared with the $\mathrm{HC}$ - period. The FEV1 was

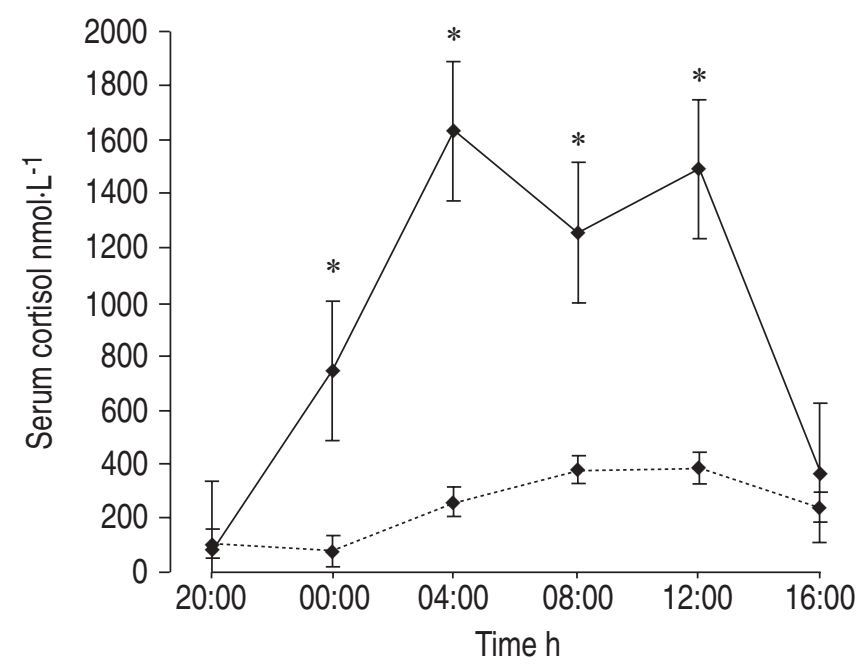

Fig. 1. - Mean \pm SEM level of serum cortisol at six different time points with $(-)$ and without $(\cdots \cdots \cdots \cdot)$ hydrocortisone infusion in the asthma group. *: $\mathrm{p}<0.05$. 


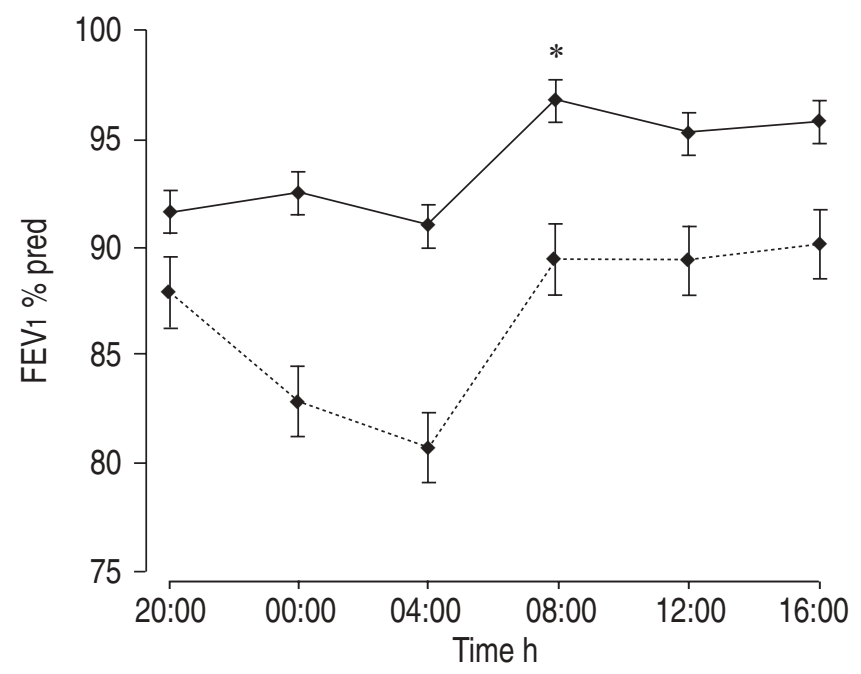

Fig. 2. - Mean \pm SEM forced expiratory volume in one second (FEV1) $\%$ predicted at six different time points with hydrocortisone infusion $(\mathrm{HC}+;-)$ and without $(\mathrm{HC}-; \cdot \cdots \cdots \cdots \cdot)$ in the nocturnal asthma group (NA+). *: $\mathrm{p}<0.05 \mathrm{HC}+$ versus $\mathrm{HC}-$ at $08.00 \mathrm{~h}$.

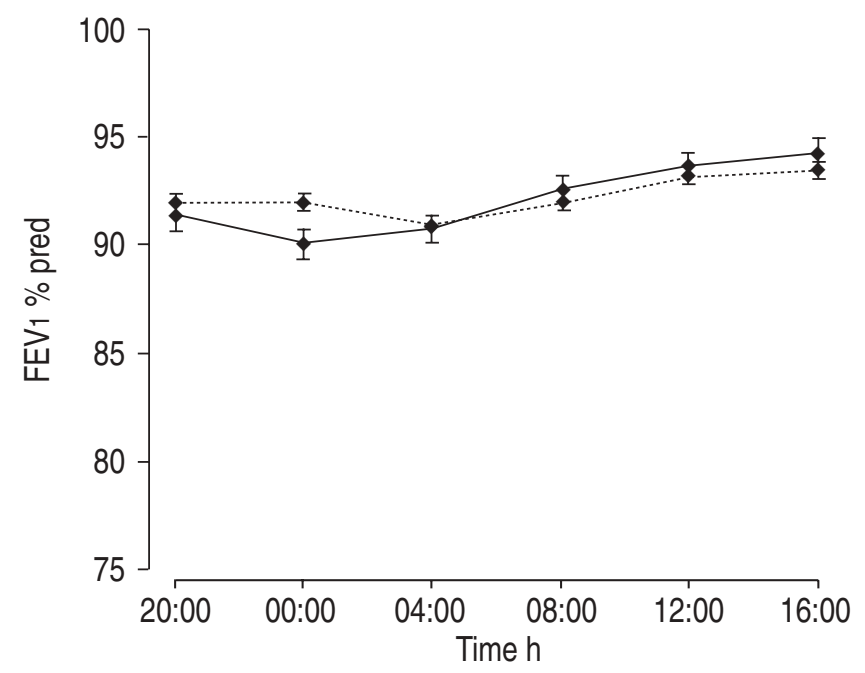

Fig. 3. - Mean \pm SEM forced expiratory volume in one second (FEV1) $\%$ predicted at six different time points with hydrocortisone infusion $(\mathrm{HC}+;-)$ and without (HC-; ……) in the non-nocturnal asthma group (NA-). significantly higher at $08: 00 \mathrm{~h}(\mathrm{p}=0.02$, fig. 2$)$, and tended to be higher at 00:00, 04:00 and 16:00 $\mathrm{h}(\mathrm{p}=0.08,0.08$ and 0.07, respectively). No significant effect of intravenous $\mathrm{HC}+$ on FEV1 values was seen in the NA- group (fig. 3).

\section{The effect of hydrocortisone infusion on eosinophils}

In the whole asthma group, numbers of eosinophils $\left(10^{9} \cdot \mathrm{L}^{-1}\right)$ were significantly lower after infusion of $\mathrm{HC}$ at 04:00 $\mathrm{h}(0.61$ $(0.05-1.42)$ versus $0.52(0.05-1.79) ; \mathrm{p}<0.05)$. No significant differences in eosinophil numbers were observed in the separate $\mathrm{NA}+$ and NA-group, although at 04:00 h the decrease almost reached significance in both groups (table 2).

\section{The effect of hydrocortisone infusion on airway hyperresponsiveness}

PD20 methacholine values did not differ between the measurements without and with $\mathrm{HC}$ at both time points in the asthma group as a whole. Values at 04:00 h without and with $\mathrm{HC}$ were $2.14(0.0-8.75)$ and $1.6(0.0-35.3) \mathrm{mg} \cdot \mathrm{mL}^{-1}$, respectively. Values at $16: 00 \mathrm{~h}$ were $2.0(0.0-34.8)$ and 1.8 $(0.2-33.1) \mathrm{mg} \cdot \mathrm{mL}^{-1}$, respectively. No significant differences in airway hyperresponsiveness with substitution of $\mathrm{HC}$ were seen between the NA+ and NA- groups (fig. 4).

PD20 AMP values did not differ significantly between the measurements without and with hydrocortisone at 04:00 and 16:00 $\mathrm{h}$ in the whole asthma group. In the NA- group, a significant increase in PD20 AMP with HC substitution at 16:00 h occurred (72.0 (0.13-144.0) versus 144.0 (2.25-144.0) $\mathrm{mg} \cdot \mathrm{mL}^{-1}$, respectively, $\mathrm{p}<0.05$; table 2$)$. One of the children in the NA+ and four of the children in the NA- did not respond to the highest AMP concentration, neither with saline, nor after substitution of $\mathrm{HC}$ (fig. 4).

\section{Discussion}

This study in asthmatic children was designed to identify whether substitution of low endogenous serum cortisol levels with intravenous $\mathrm{HC}$ would lead to improvement of the 24-h FEV1 variation and/or improvement of (nocturnal) inflammatory parameters. Infusion of $\mathrm{HC}$ resulted in a significant increase in cortisol levels in all asthmatic children during the night and morning hours. This resulted in higher FEV1 values at all time points in the children with nocturnal asthma,

Table 2.-Eosinophils, provocative dose causing a $20 \%$ fall in forced expiratory volume in one second (PD20), adenosine $5^{\prime}$-monophosphate (AMP) and PD20 methacholine in asthmatic children with (NA+) and without (NA-) nocturnal asthma, with and without hydrocortisone substitution ( $\mathrm{HC}+$ and $\mathrm{HC}-$, respectively)

\begin{tabular}{|c|c|c|c|c|}
\hline & \multicolumn{2}{|c|}{$\mathrm{NA}+$} & \multicolumn{2}{|c|}{ NA- } \\
\hline & $\mathrm{HC}-$ & $\mathrm{HC}+$ & $\mathrm{HC}-$ & $\mathrm{HC}+$ \\
\hline \multicolumn{5}{|c|}{ Eosinophils $10^{9} \cdot \mathrm{L}^{-1}$} \\
\hline $04: 00 \mathrm{~h}$ & $0.79(0.05-1.42)$ & $0.55(0.06-1.79)$ & $0.60(0.08-0.90)$ & $0.48(0.05-0.83)$ \\
\hline $16: 00 \mathrm{~h}$ & $0.65(0.01-1.56)$ & $0.41(0.04-1.70)$ & $0.39(0.05-0.77)$ & $0.32(0.07-0.73)$ \\
\hline \multicolumn{5}{|c|}{$\mathrm{PD} 20 \mathrm{AMP} \mathrm{mg} \cdot \mathrm{mL}^{-1}$} \\
\hline 04:00 h & $13.50(0.0-126.0)$ & $14.60(0.0-72.0)$ & $48.40(0.3-139.5)$ & $98.40(0.2-135.0)$ \\
\hline $16: 00 \mathrm{~h}$ & $36.00(0.0-144.0)$ & $45.00(0.56-132.8)$ & $72.00(0.1-144.0)^{*}$ & $144.00(2.3-144.0)^{*}$ \\
\hline \multicolumn{5}{|c|}{ PD20 methacholine $\mathrm{mg} \cdot \mathrm{mL}^{-1}$} \\
\hline 04:00 h & $1.01(0.00-8.8)$ & $0.34(0.0-35.3)$ & $2.14(0.2-8.75)$ & $2.14(0.2-35.3)$ \\
\hline $16: 00 \mathrm{~h}$ & $1.47(0.00-8.3)$ & $1.01(0.2-33.1)$ & $3.00(0.3-34.8)$ & $2.97(0.2-33.1)$ \\
\hline
\end{tabular}

Data are expressed as median (range). *: p $<0.05$ HC- versus $\mathrm{HC}+$. 

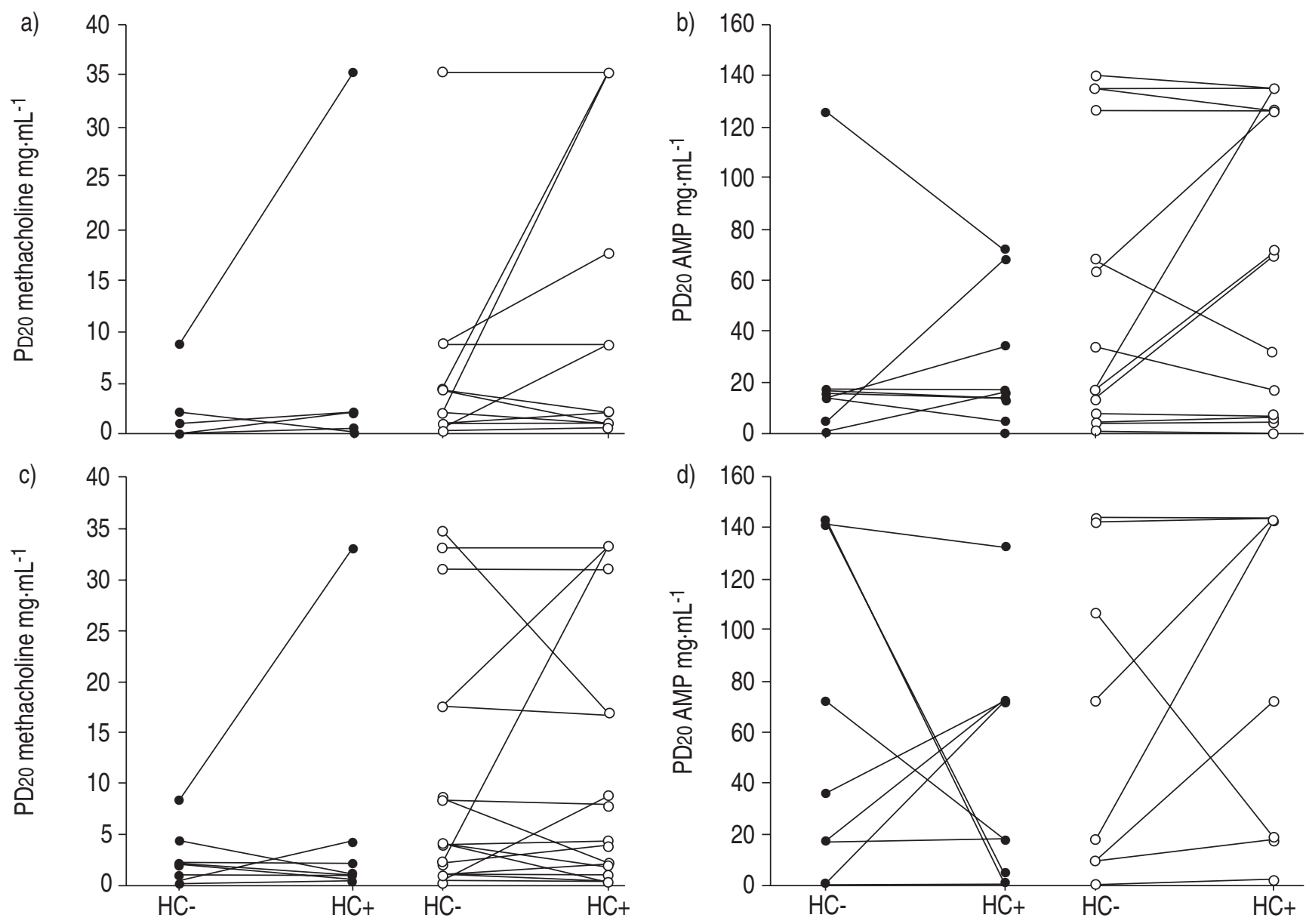

Fig. 4. - Bronchial responsiveness to methacholine (a and $\mathrm{c}$ ) and adenosine 5'-monophosphate (AMP; $\mathrm{b}$ and d). Individual provocative dose causing a $20 \%$ fall in forced expiratory volume in one second (PD20) methacholine and AMP values at 04:00 (a and b) and 16.00 h (c and d) with hydrocortisone infusion $(\mathrm{HC}+)$ and without $(\mathrm{HC}-)$ in the nocturnal $(\bullet)$ and non-nocturnal asthma group $(\bigcirc)$.

defined by a $24-\mathrm{h}$ FEV1 variation $\geqslant 15 \%$. This phenomenon was not seen in the non-nocturnal asthma group. Furthermore, the number of blood eosinophils decreased significantly after infusion of $\mathrm{HC}$ at 04:00 $\mathrm{h}$ for the asthma group as a whole. The current study found no significant effect of intravenous $\mathrm{HC}+$ on the severity of airway hyperresponsiveness, measured with methacholine and AMP, neither at 04:00 $\mathrm{h}$ nor at 16:00 $\mathrm{h}$, apart from a significant improvement in PD20 AMP at 16:00 h in the NA-group.

The effect of $\mathrm{HC}$ on lung function has, to date, only been studied in adult patients with asthma [5, 14, 20-22]. The results of these older studies are conflicting, most likely due to methodological flaws. Ellul-MiCALleF and FENECH [20] showed that in 10 steroid-naive asthmatic adults admitted to the hospital with poor lung function values (FEV1 36-73\% pred), a single intravenous injection of $40 \mathrm{mg}$ prednisolone phosphate resulted in a consistent improvement in FEV1. The peak effect occurred at $8 \mathrm{~h}$ after the injection and changes were still significant after $30 \mathrm{~h}$. However, this was an open and uncontrolled study and the improvement may well have been due to the hospital admission itself. In an earlier study, the current authors have shown that hospital admission of asthmatic children without any other medical intervention resulted in improvement of their nocturnal lung function values [12]. SOUTAR et al. [14] tried to prevent the nocturnal fall in peak expiratory flow (PEF) by intravenous HC infusion in six adult asthmatics. Early morning asthma and the nocturnal fall in PEF persisted in five of these patients.
RAMSDELL et al. [21] studied nine asymptomatic untreated asthmatic adults who received either a single dose of $8 \mathrm{mg} \cdot \mathrm{kg}^{-1} \mathrm{HC}$ or saline as a placebo, in a double-blind crossover format. FEV1 was measured every 15 minutes in the first hour, then every $30 \mathrm{~min}$ up to $6 \mathrm{~h}$. They showed a linear trend of improvement in FEV1 with HC. More recently, BEAM et al. [23] studied the effect of a supraphysiological dose of intravenously administered $\mathrm{HC}$ in 11 adult patients with nocturnal worsening of their asthma. Despite the fact that nine of these 11 patients were maintained on daytime prednisone therapy, they still demonstrated improvement in their overnight decrement in FEV1, varying from $23-66 \%$. Contrary to the previously described studies, the present authors have studied asthmatic children with lung functions within the normal range in both the nocturnal and non-nocturnal group. In the present study, an intervention dose of $30 \mathrm{mg} \cdot \mathrm{m}^{-2}$ body surface was chosen. Converted to an oral prednisone dose this approximates a total dose of $7.5 \mathrm{mg} \cdot 24 \mathrm{~h}^{-1}$. The current authors aimed to administer a dose that was sufficiently high to abolish the physiological nocturnal decrease in endogenous cortisone. The results indicate that this indeed leads to higher FEV1 values at all time points in the group with nocturnal asthma. Together with the previous observation that asthmatic children have lower FEV1 values and cortisol levels than healthy children, this signifies the importance of cortisol in the pathophysiology of asthma. The underlying mechanism of this effect is not fully clear. It is possible that the supranormal blood levels of 
cortisol reached by HC treatment mainly causes decreased oedema of the airway wall, thereby improving FEV1 especially in the children with more severe airway wall oedema, i.e. the $\mathrm{NA}+$ group. Thus, oedema reduction may play a large role, next to a theoretically plausible antiinflammatory effect.

Tissue eosinophilia is a well-recognised feature in the inflammatory process of asthma, which is thought to be reflected by peripheral blood eosinophilia. Earlier findings of the present authors' group in adult patients with asthma have shown that mucosal airway wall inflammation is more extensive in those asthmatics who experience symptoms at night than in those who do not have nocturnal symptoms $[6,13]$. However, this appears to be true both at 04:00 and 16:00 h. In the present study, the blood eosinophil counts tended to be higher in the NA+ than in the NA- group both at 04:00 and 16:00 h, but not significantly so, most likely due to the relatively small number of children in this study.

An inverse relationship between serum cortisol and the number of eosinophils was demonstrated previously in animals as well as in patients with allergic asthma. FORNHEM et al. [24] observed a marked lung tissue eosinophilia in low cortisol-sensitised pigs compared with control animals. In allergic asthmatic patients, inhaled corticosteroids can reduce the cellular infiltration of eosinophils in bronchial biopsies to normal levels [25]. Further, WILSON and LIPWORTH [26] found a significant dose-related suppression of blood eosinophils in 12 adult asthmatics with both oral prednisolone (dose range 5-20 mg) and inhaled fluticasone propionate (dose range 440-1760 $\mu \mathrm{g}$ b.i.d.). The results of these studies are in line with the current authors' observations. HC infusion resulted in relatively high cortisol levels during the night in association with a decrease in blood eosinophil count, which reached significance at 04:00 $\mathrm{h}$ for the asthma group as a whole. The absence of a significant decrease in eosinophils at 16:00 h may be explained by the negative feedback mechanism of the hypothalamic-pituitary-adrenal cortisol axis after $20 \mathrm{~h}$ of $\mathrm{HC}$ infusion, leading to similar cortisol levels at 16:00 h during $\mathrm{HC}$ and saline infusion.

The current study did not observe an effect of intravenous $\mathrm{HC}$ on bronchial hyperresponsiveness, neither with methacholine which directly acts on receptors of airways smooth muscles, nor by AMP which indirectly leads to smooth muscle contraction. This is in contrast with the well-known positive effect of inhaled corticosteroids on the severity of bronchial hyperresponsiveness in children with asthma [27]. However, a number of studies with systemic steroids showed a limited or no effect what so ever on the severity of airway responsiveness. JENKINS and WoOLCOCK [28] compared the effect of 3-weeks treatment with inhaled beclomethasone dipropionate $(1,200 \mu \mathrm{g})$ and oral prednisolone $(12.5 \mathrm{mg})$ in 18 adult asthmatics. The authors found a significant improvement in PD20 histamine with beclomethasone dipropionate but no change in PD20 histamine with prednisone treatment, illustrating the superior topical anti-inflammatory effect of inhaled corticosteroids. In the same way MEIJER et al. [29] showed that 2 weeks of treatment with high-dose inhaled fluticasone $(2,000 \mu \mathrm{g})$ is more effective in improving airway hyperresponsiveness to both methacholine and AMP than oral prednisolone $(30 \mathrm{mg})$.

The process to reduce airway responsiveness appears to be slow. VAN ESSEN-ZANDVLIET et al. [30] showed an ongoing improvement in PD20 histamine during treatment with inhaled corticosteroids in asthmatic children, with a stabilisation after 20 months at 2.1 doubling doses above baseline. The other way around, WAALKENS et al. [31] showed that PD20 histamine still continued to decrease 4 months after cessation of long-term treatment with inhaled steroids. The present study did not find any effect on bronchial hyperresponsiveness after intravenous HC. There may be several possible explanations. The above explanation by the route of administration is a likely one. Furthermore, the children had stopped their inhaled corticosteroids for 2 weeks before the onset of the study after a longer continuous period of treatment with inhaled steroids. This may have stabilised airway responsiveness. The period when maintenance medication was withdrawn might well have been too short to expect an effect of intravenous hydrocortisone, specially with the dose used. Notwithstanding this, the only change in responsiveness observed was with AMP, a stimulus that is known to better reflect airway wall inflammation than the conventional stimulus methacholine [32]. Another contributing factor could be that, specifically, the thickening below the basement membrane resulting from inflammatory processes $[25,33]$ (remodelling) could not be changed by intravenous HC over such a short time span.

In conclusion, the current study shows that substitution of lower endogenous 24-h values of cortisol, specifically improves lung function at the nadir time points of circadian cortisol levels. Together with the previous observation that asthmatic children have lower forced expiratory volume in one second values and cortisol levels than healthy children, this signifies the importance of cortisol in the pathophysiology of asthma. Furthermore, a short period of hydrocortisone infusion reduces the number of circulating eosinophils, which can be considered as a marker of inflammation, whereas it does not change the severity of airway hyperresponsiveness.

\section{References}

1. Mackay TW, Wallace WAH, Howie SEM, et al. Role of inflammation in nocturnal asthma. Thorax 1994; 49: 257262.

2. Martin RJ, Cicutto LC, Smith HR, Ballard RD, Szefler SJ. Airways inflammation in nocturnal asthma. Am Rev Respir Dis 1991; 143: 351-357.

3. Postma DS, Keyzer JJ, Koëter GH, Sluiter HJ, De Vries K. Influence of the parasympathetic and sympathetic nervous system on nocturnal bronchial obstruction. Clin Science 1985; 69: 251-258.

4. Morrison JFJ, Pearson SB, Dean HG. Parasympathetic nervous system in nocturnal asthma. BMJ 1988; 296: 14271429.

5. Barnes PJ, Fitzgerald G, Brown MJ, Dollery C. Nocturnal asthma and changes in circulating epinephrine, histamine and cortisol. N Engl J Med 1980; 303: 263-267.

6. Oosterhoff Y, Kauffman HF, Rutgers B, Zijlstra FJ, Koëter GH, Postma DS. Inflammatory cell number and mediators in bronchoalveolar lavage fluid and peripheral blood in subjects with asthma with increased nocturnal airways narrowing. J Allergy Clin Immunol 1995; 96: 219229.

7. van Aalderen WMC, Postma DS, Koëter GH, Knol K. Nocturnal airflow obstruction, histamine, and the autonomic central nervous system in children with allergic asthma. Thorax 1991; 46: 366-371.

8. Hacken ten NHT. Airway inflammation in nocturnal asthma. Groningen, van Denderen BV, 1998.

9. Jarjour NN, Busse WW. Cytokines in bronchoalveolar lavage fluid of patients with nocturnal asthma. Am J Respir Crit Care Med 1995; 152: 1474-1477.

10. Silkoff PE, Martin RJ. Pathophysiology of nocturnal asthma. Ann Allergy Asthma Immunol 1998; 81: 378-387.

11. Oosterhoff Y, Koëter GH, Monchy de JGR, Postma DS. Circadian variation in airways responsiveness to methacholine, propanolol, and AMP in atopic asthmatic subjects. Am Rev Respir Dis 1993; 147: 512-517.

12. van Aalderen WMC, Postma DS, Koëter GH, Knol K. 
Circadian change in bronchial responsiveness and nocturnal airflow obstruction in asthmatic children. Thorax 1989; 44: 803-807.

13. Hacken ten NHT, Tiemens W, Smith M, Drok D, Kraan J, Postma DS. Increased peak expiratory flow variation in asthma: severe persistent increase but not nocturnal worsening of airway inflammation. Eur Respir $J$ 1998; 12: $546-550$.

14. Soutar CA, Costello J, Ijaduola O, Turner-Warwick M. Nocturnal and morning asthma. Thorax 1975; 30: 436-440.

15. Durham SR, Keenan J, Cookson WOCM, Craddock CF, Benson MK. Diurnal variation in serum cortisol concentrations in asthmatic subjects after allergen inhalation. Thorax 1989; 44: 582-585.

16. Kraft M, Pak J, Martin RJ. Serum cortisol in asthma: marker of nocturnal worsening of symptoms and lung function? Chronobiol Int 1998; 15: 85-92.

17. Sparrow D, O'Connor GT, Rosner B, Demolles D, Weiss ST. A longitudinal study of plasma cortisol concentration and pulmonary function decline in men. Am Rev Respir Dis 1993; 147: $1345-1348$

18. Kauffmann F, Guiochon-Mantel A, Neukirch F. Is low endogenous cortisol a risk factor for asthma? Am J Respir Crit Care Med 1999; 160: 1428-1428.

19. Landstra AM, Boezen HM, Postma DS, van Aalderen WM. Role of serum cortisol levels in children with asthma. Am J Respir Crit Care Med 2002; 165: 708-712.

20. Ellul-Micallef R, Fenech FF. Intravenous prednisolone in chronic bronchial asthma. Thorax 1975; 30: 312-315.

21. Ramsdell JW, Berry CC, Clausen JL. The immediate effects of cortisol on pulmonary function in normals and asthmatics. J Allergy Clin Immunol 1983; 71: 69-74.

22. Reinberg A, Gervais P, Chaussade M, Fraboulet G, Dudurque B. Circadian changes in effectiveness of corticosteroids in eight patients with allergic asthma. J Allergy Clin Immunol 1982; 71: 425-433.

23. Beam RW, Ballard RD, Martin RJ. Spectrum of corticosteroid sensitivity in nocturnal asthma. Am Rev Respir Dis 1992; 145: 1082-1086.

24. Fornhem C, Peterson CG, Scheynius A, Alving K. Influence of endogenous cortisol on eosinophil function in sensitized pigs: direct measurements of eosinophil peroxidase. Clin Exp Allergy 1996; 26: 469-478.

25. Smith H. Asthma, inflammation, eosinophils and bronchial hyperresponsiveness. Clin Exp Allergy 1992; 22: 187197.

26. Wilson AM, Lipworth BJ. Short-term dose-response relationships for the relative systemic effects of oral prednisolone and inhaled fluticasone in asthmatic adults. $\mathrm{Br} J$ Clin Pharmacol 1999; 48: 579-585.

27. van Essen-Zandvliet EEM, Hughes MD, Waalkens HJ, Duiverman EJ, Pocock SJ, Kerrebijn KF and and the Dutch CNSLD Study Group. Effects of 22 months' treatment with inhaled corticosteroids and/or beta-2-agonists on lung function, airway responsiveness and symptoms in children with asthma. Am Rev Respir Dis 1992; 146: 547-554.

28. Jenkins CR, Woolcock AJ. Effect of prednisone and beclomethasone dipropionate on airway responsiveness in asthma: a comparative study. Thorax 1988; 43: 378-384.

29. Meijer RJ, Kerstjens HA, Arends LR, Kauffman HF, Koëter GH, Postma DS. Effects of inhaled fluticasone and oral prednisolone on clinical and inflammatory parameters in patients with asthma. Thorax 1999; 54: 894-899.

30. van Essen-Zandvliet EEM, Hughes MD, Waalkens HJ, Duiverman EJ, Kerrebijn KF. Remission of childhood asthma after long-term treatment with inhaled corticosteroid (budesonide): can it be achieved? Dutch CNSLD Study Group. Eur Respir J 1994; 7: 63-68.

31. Waalkens HJ, van Essen-Zandvliet EEM, Hughes MD, et al. Cessation of long-term treatment with inhaled corticosteroids (budesonide) in children with asthma results in deterioration. The Dutch CNSLD Study Group. Am Rev Respir Dis 1993; 148: 1252-1257.

32. van Den Berge M, Meijer RJ, Kerstjens H, et al. PC (20) adenosine 5'monophosphate is more closely associated with airway inflammation in asthma than PC (20) methacholine. Am J Respir Crit Care Med 2001; 163: 1546-1550.

33. Laitinen LA, Laitinen A. Remodeling of asthmatic airways by glucocorticosteroids. J Allergy Clin Immunol 1996; 97: $153-158$. 